\title{
Effects of Agriculture Base Educational Intervention on Rural School Students' Awareness and Attitudes toward Agriculture
}

\author{
Gaikwad N, Shaikh R, Shinde P \\ Senior Scientist, AICRP- Human Development, College of Home Science , MKV Parbhani (Maharashtra) \\ Junior Research Fellow, AICRP- Human Development, College of Home Science MKV Parbhani
}

\begin{abstract}
A sample of randomly selected 300 rural school students from Std $7^{\text {th }}$, Std $8^{\text {th }}$ and Std $9^{\text {th }}$ were included in this study. Out of 300 rural school students 150 (75-girls and 75-boys) from Narsinha Vidyalaya Pokharni belonged to experimental group and the remaining 150 students from Narsinha Vidyalaya Lohgaon of Parbhani district of same standard were selected and it was considered as control group. Prior to the initiation of the experiment, scales developed by AICRP-HD component for assessment of SES, awareness about agriculture and attitudes toward agriculture were administered on both the groups'. The experimental groups' students were educated in the village for 3-4 hrs in a day, weekly twice by investigators regularly and by experts 3-4 times during the intervention by organizing series of lectures, quiz competition, exhibition and providing free of cost literature related to agriculture developed by MKV Parbhani. After implementing the intervention of awareness about agriculture and attitudes toward agriculture for a period of 3 months, all the sample rural school students in the experimental and control groups were reassessed for studying the effects of implemented agriculture base educational intervention. The experimental rural school students' post test result i.e awareness about agriculture and attitudes toward agriculture were compared with control group. It is concluded that agriculture based educational intervention on selected aspects of agriculture to rural school students' about awareness and attitudes toward agriculture found to be significantly useful in enhancing the awareness and attitudes of rural school students toward selected aspects of agriculture. Therefore rural school students need a positive agriculture based educational intervention for their contribution in agriculture.
\end{abstract}

\section{Objectives}

- To enroll rural school students for experimental \& control group

- To implement agriculture base educational intervention for the experimental group rural school students

- To study the effects of implemented agriculture base educational intervention on the rural school students' awareness and attitudes toward agriculture by comparing it with control group school students

\section{Methodology}

For contribution of youth in agriculture through agriculture base educational intervention, 300 rural school girls and boys students were purposely selected. Out of 300 students 150 (75- girls \& 75-boys) belonged to experimental group (Gr I) of Std $7^{\text {th }}$, Std $8^{\text {th }}$ and Std $9^{\text {th }}$ of Narsinha Vidyalaya, Pokharni and the remaining 150 students of same standard from the Narsinha Vidylaya Lohgaon from Parbhani district were selected randomly and it was considered as control group (Gr II). Prior to the initiation of the experiment, SES scale, awareness checklist on agriculture and attitude scale on agriculture developed by AICRP-HD unit were administered on both groups' students. The rural school students of experimental group were educated by organizing series of lectures, quiz competition, exhibition and providing free of cost literature on agriculture developed by MKV Parbhani. After doing the assessment the agriculture base educational intervention was planned for the experimental group (Gr I) students. The agriculture base educational intervention was executed in the village for 3-4 hrs in a day, weekly twice by the investigators regularly and by experts 3-4 times during the intervention. After implementing the intervention on awareness about agriculture and attitudes toward agriculture of experimental group's students for a period of 3 months both the groups were reassessed for studying the effects of implemented intervention. The collected data was pooled, analyzed and discussed.

Tools used for the research

Socio-Economic Status Scale: The Socio-economic status scale consists of parameters such as caste, religion, family type and size, parents education and occupation, type of house and size, type of agricultural land (irrigated/ rainfed), milch animals, material possession, water facility, electricity and drainage. The summated score is categorized as low, medium and high. 
Awareness checklist on agriculture: Checklist comprises of total 32 items scored 1 for yes and zero for no response respectively. It includes awareness on soil \& water conservation, organic farming development, use of chemical fertilizer \& pesticide, cropping system and food processing \& livelihood security related questions.

\begin{tabular}{|l|l|}
\hline \multicolumn{1}{|c|}{ Score } & \multicolumn{1}{c|}{ Category } \\
\hline Below 10 & Poor \\
\hline $10-21$ & Average \\
\hline Above 21 & Good \\
\hline
\end{tabular}

Attitude scale on agriculture: The scale consists of total 25 items scored for positive statements as $3,2,1$ and vice- versa for negative statements. The statements include importance of agriculture, education in agriculture and career opportunities in agriculture.

\begin{tabular}{|l|l|}
\hline \multicolumn{1}{|c|}{ Score } & \multicolumn{1}{c|}{ Category } \\
\hline $25-42$ & Unfavorable \\
\hline $43-59$ & Neutral \\
\hline $60-75$ & Favorable \\
\hline
\end{tabular}

\section{Findings}

Table 1 indicates that significantly a higher percentage of the control group (Gr II) rural students mothers were non literate as compare to experimental group rural school students' mothers. There were no significant differences found in the SES of rural school students in both the groups. No significant differences were recorded in the remaining parameters of students of experimental \& control groups.

Table 2 depicts the agriculture awareness mean scores of the sample rural school students in both the experimental groups (Gr I \& Gr II). The experimental group and control groups' awareness mean scores ranged between $2.89 \pm 1.67 \& 2.84 \pm 1.64$ prior to the initiation of intervention. After implementing the intervention on soil \& water conservation for the experimental groups (Gr I) awareness about it raised to $4.60 \pm 1.36$, while it was almost the same $(2.90 \pm 1.64)$ in the control group $(\mathrm{Gr}$ II). There was significant increase in rural school students' awareness about soil \& water conservation. The organic farming development awareness mean scores of rural school students of both the experimental group and control group ranged between $2.37 \pm 1.39 \& 2.30 \pm$ 1.36 prior to the initiation of intervention. After implementing the intervention on organic farming development to the experimental group rural school students it raised to $3.72 \pm 1.23$ while it was same $(2.30 \pm 1.36)$ in the control group. There was significant increase in rural school students' awareness about organic farming development after receiving the intervention.

The awareness mean scores about use of chemical fertilizers \& pesticides of the rural school students of both the experimental groups (Gr I \& Gr II) ranged between $2.79 \pm 1.60 \& 2.74 \pm 1.54$ prior to initiation of the intervention. The awareness mean scores of use of chemical fertilizers \& pesticides of experimental group (Gr I) students increased to $4.40 \pm 1.37$ while it was almost same in the control group. There was significant increase in the awareness of use of chemical fertilizers \& pesticides of experimental groups' (Gr I) students.

The mean scores of awareness about food processing \& livelihood security in both the experimental groups ranged between $3.52 \pm 1.91 \& 3.43 \pm 1.85$ prior to the initiation of intervention. After receiving intervention the awareness of rural school students about food processing \& livelihood security raised to $5.49 \pm$ 1.59. There was significant increase in the awareness of food processing \& livelihood security of experimental group's students (Gr I).

General awareness toward agriculture mean scores of rural school students ranged between $15.68 \pm$ $6.89 \& 15.36 \pm 6.63$ prior to the implementation of intervention. After completion of 3 months duration agriculture base educational intervention towards agriculture, awareness mean scores of the experimental group (Gr I) raised to $24.36 \pm 5.49$, while it was almost the same $(15.57 \pm 6.58)$ in the control group.

The result clearly indicate from table 3 that the attitudes mean scores of rural school students' toward importance of agriculture in both the experimental and control group (Gr I \& Gr II) ranged between $19.73 \pm$ $4.13 \& 19.69 \pm 4.09$ prior to initiation of intervention. After receiving intervention the rural school students' attitudes toward importance of agriculture in the experimental group (Gr I) was raised to $26.31 \pm 4.22$ while in the control group (Gr II) it was almost same $(19.88 \pm 4.08)$. There was significant increase in the school students' attitudes toward importance of agriculture. After receiving intervention package with regard to education in agriculture the rural school students' mean scores prior to the initiation of intervention ranged between 12.55

$\pm 2.79 \& 12.54 \pm 2.68$ in both the experimental and control group (Gr I \& Gr II). However after the completion of the intervention the attitudes mean scores of experimental group ( Gr I) rural school students' toward education in agriculture increased to $16.97 \pm 2.95$, while it was only $12.7 \pm 2.59$ in the control group. There was significant positive change in the attitudes of rural school students toward education in agriculture. After giving intervention with regard to career opportunities, the sample rural school students' attitudes score ranged between $8.74 \pm 2.21 \& 8.71 \pm 2.13$ prior to the initiation of intervention. After completion of the intervention, it 
increased to $17.09 \pm 2.90$ in the experimental group (Gr I) \& there was almost no increase in the attitudes of rural school students of the control group about career opportunity.

The mean scores of general attitudes toward agriculture of rural school students of both the experimental groups were ranged between $44.66 \pm 8.42$ and $44.69 \pm 8.26$ prior to the implementation of agriculture base educational intervention. After completion of intervention for a period of 3 months on attitudes toward agriculture, their mean scores of attitude in the experimental group ( Gr I) raised to $60.63 \pm 9.03$ while it was almost same $(45.05$ $\pm 8.07)$ in the control group. The findings indicate that the intervention on attitudes toward agriculture helps in significantly enhancing the attitudes of the rural school students about it.

\section{Conclusion}

Agriculture base educational intervention on selected aspects of agriculture to rural school students' about awareness and attitudes toward agriculture found to be significantly useful in enhancing the awareness and attitudes of rural school students toward selected aspects of agriculture. Therefore rural school students need a positive agriculture based educational intervention for their contribution in agriculture.

Table 1 Background information of experimental group and control group rural school students

\begin{tabular}{|c|c|c|c|}
\hline \multirow{2}{*}{$\begin{array}{r}\text { Parameters } \\
\text { SES of family }\end{array}$} & \multicolumn{2}{|c|}{$\begin{array}{c}\text { Number of rural school } \\
\text { students }\end{array}$} & \multirow[t]{2}{*}{ ' $z$ ' values } \\
\hline & $\begin{array}{c}\text { Experimenta } \\
\text { l } \\
\text { Group } \\
\text { n-150 }\end{array}$ & $\begin{array}{c}\text { Control } \\
\text { Group } \\
\text { n-150 }\end{array}$ & \\
\hline Low & 51 & 54 & $0.36^{\mathrm{NS}}$ \\
\hline Medium & 99 & 96 & $1.67^{\mathrm{NS}}$ \\
\hline \multicolumn{4}{|l|}{ Family type } \\
\hline Nuclear & 94 & 93 & $0.35^{\mathrm{NS}}$ \\
\hline Joint & 55 & 57 & $0.34^{\mathrm{NS}}$ \\
\hline \multicolumn{4}{|l|}{ Family size } \\
\hline Small & 72 & 66 & $1.12^{\mathrm{NS}}$ \\
\hline Medium & 71 & 72 & $0.19^{\mathrm{NS}}$ \\
\hline Large & 07 & 12 & $1.48^{\mathrm{NS}}$ \\
\hline \multicolumn{4}{|l|}{ Gender } \\
\hline Boys & 75 & 75 & ---- \\
\hline Girls & 75 & 75 & ---- \\
\hline \multicolumn{4}{|l|}{ Chronological age (yrs) } \\
\hline 12 & 05 & 12 & $2.19^{\mathrm{NS}}$ \\
\hline 13 & 52 & 48 & $0.69^{\mathrm{NS}}$ \\
\hline 14 & 56 & 54 & $0.34^{\mathrm{NS}}$ \\
\hline 15 & 37 & 36 & $0.17^{\mathrm{NS}}$ \\
\hline \multicolumn{4}{|l|}{ Ordinal position } \\
\hline First born & 36 & 34 & $0.36^{\mathrm{NS}}$ \\
\hline Second born & 54 & 48 & $1.04^{\mathrm{NS}}$ \\
\hline Third born & 35 & 47 & $2.12 *$ \\
\hline Fourth born & 19 & 18 & $0.22^{\mathrm{NS}}$ \\
\hline Fifth \& above born & 06 & 03 & $1.25^{\mathrm{NS}}$ \\
\hline \multicolumn{4}{|l|}{ Maternal education } \\
\hline Non literates & 58 & 71 & $2.37 * *$ \\
\hline Primary educated & 68 & 62 & $1.09^{\mathrm{NS}}$ \\
\hline High school educated & 24 & 17 & $1.50^{\mathrm{NS}}$ \\
\hline \multicolumn{4}{|l|}{ Paternal education } \\
\hline Non literates & 17 & 18 & $0.22^{\mathrm{NS}}$ \\
\hline Primary school educated & 59 & 58 & $0.17^{\mathrm{NS}}$ \\
\hline High School educated & 58 & 59 & $0.17^{\mathrm{NS}}$ \\
\hline Intermediate educated & 16 & 15 & $0.23^{\mathrm{NS}}$ \\
\hline
\end{tabular}

Gr I - Experimental group

*- Significant at 0.05 level
Gr II - Control group

**- Significant at 0.01 level NS - Non significant 
Table 2 Comparison between awareness mean scores of rural school students about agriculture in control and Experimental groups

\begin{tabular}{|c|c|c|c|c|c|c|c|c|}
\hline \multirow{3}{*}{$\begin{array}{l}\text { Selected aspects } \\
\text { of agriculture } \\
\text { awareness }\end{array}$} & \multicolumn{8}{|c|}{ Awareness mean scores of experimental groups students } \\
\hline & \multicolumn{3}{|c|}{$\begin{array}{c}\text { Experimental Group } \\
(\mathrm{n}-150)\end{array}$} & \multicolumn{3}{|c|}{$\begin{array}{c}\text { Control Group } \\
(\mathrm{n}-150)\end{array}$} & \multicolumn{2}{|c|}{ 'z' values } \\
\hline & $\begin{array}{c}\text { Pre test } \\
\text { Mean } \pm \text { SD } \\
\text { a }\end{array}$ & $\begin{array}{c}\text { Post test } \\
\text { Mean } \pm \text { SD } \\
\text { b }\end{array}$ & ' $z$ ' values & $\begin{array}{c}\text { Pre test } \\
\text { Mean } \pm \text { SD } \\
\text { c }\end{array}$ & $\begin{array}{c}\text { Post test } \\
\text { Mean } \pm \text { SD } \\
\text { d }\end{array}$ & ' $z$ ' values & a Vsc & b Vs d \\
\hline $\begin{array}{l}\text { Soil \& water } \\
\text { conservation }\end{array}$ & $2.89 \pm 1.67$ & $4.60 \pm 1.36$ & $9.72^{* * *}$ & $2.84 \pm 1.64$ & $2.90 \pm 1.64$ & $0.31^{\mathrm{Ns}}$ & $0.08 \mathrm{Ns}$ & $9.77 * *$ \\
\hline $\begin{array}{l}\text { Organic farming } \\
\text { development }\end{array}$ & $2.37 \pm 1.39$ & $3.72 \pm 1.23$ & $8.90 * *$ & $2.30 \pm 1.36$ & $2.30 \pm 1.36$ & $0.57 \mathrm{Ns}$ & $0.44 \mathrm{Ns}$ & $8.91 * *$ \\
\hline $\begin{array}{l}\text { Use of chemical } \\
\text { fertilizers \& } \\
\text { pesticides }\end{array}$ & $2.79 \pm 1.60$ & $4.40 \pm 1.37$ & $9.36 * *$ & $2.74 \pm 1.57$ & $2.78 \pm 1.57$ & $0.22 \mathrm{Ns}$ & $0.27 \mathrm{Ns}$ & $9.52 * *$ \\
\hline Cropping system & $4.09 \pm 1.92$ & $6.14 \pm 1.57$ & $10.12^{* *}$ & $4.03 \pm 1.89$ & $4.06 \pm 1.88$ & $0.13^{\mathrm{NS}}$ & $0.27 \mathrm{Ns}$ & $10.40 * *$ \\
\hline $\begin{array}{l}\text { Food processing \& } \\
\text { livelihood security }\end{array}$ & $3.52 \pm 1.91$ & $5.49 \pm 1.59$ & $9.70 * *$ & $3.43 \pm 1.85$ & $3.48 \pm 1.83$ & $0.23 \mathrm{Ns}$ & $0.41^{\mathrm{NS}}$ & $10.15^{* *}$ \\
\hline $\begin{array}{l}\text { General awareness } \\
\text { toward agriculture }\end{array}$ & $15.68 \pm 6.89$ & $24.36 \pm 5.49$ & $12.10 * *$ & $15.36 \pm 6.63$ & $15.57 \pm 6.58$ & $0.27 \mathrm{Ns}$ & $0.40 \mathrm{Ns}$ & $12.56^{* * *}$ \\
\hline
\end{tabular}

Gr I - Experimental group Gr II - Control group

*- Significant at 0.05 level $\quad * *_{-} \quad$ Significant at 0.01 level $\quad$ NS - Non significant

Table 3 Comparison between attitudes mean scores of rural school students toward agriculture in control and experimental groups

\begin{tabular}{|c|c|c|c|c|c|c|c|c|}
\hline \multirow{3}{*}{$\begin{array}{l}\text { Selected } \\
\text { aspects of } \\
\text { attitudes } \\
\text { toward } \\
\text { agriculture }\end{array}$} & \multicolumn{8}{|c|}{ Attitudes mean scores of experimental groups students } \\
\hline & \multicolumn{3}{|c|}{$\begin{array}{c}\text { Experimental Group } \\
(\mathrm{n}-150)\end{array}$} & \multicolumn{3}{|c|}{$\begin{array}{c}\text { Control Group } \\
(\mathrm{n}-150)\end{array}$} & \multicolumn{2}{|c|}{ 'z' values } \\
\hline & $\begin{array}{c}\text { Pre test } \\
\text { Mean }+ \text { SD } \\
\text { a }\end{array}$ & $\begin{array}{c}\text { Post test } \\
\text { Mean }+ \text { SD } \\
\text { b }\end{array}$ & $\begin{array}{c}\text { ' } z \text { ' } \\
\text { values }\end{array}$ & $\begin{array}{c}\text { Pre test } \\
\text { Mean }+S D\end{array}$ & $\begin{array}{c}\text { Post test } \\
\text { Mean }+ \text { SD } \\
\text { d }\end{array}$ & ' $z$ ' values & aVsc & bVsd \\
\hline $\begin{array}{l}\text { Importance of } \\
\text { agriculture }\end{array}$ & $19.73 \pm 4.13$ & $26.31 \pm 4.22$ & $13.64 * *$ & $19.69 \pm 4.09$ & $19.88 \pm 4.08$ & $0.40^{\mathrm{NS}}$ & $0.08 \mathrm{NS}$ & $13.41^{* *}$ \\
\hline $\begin{array}{l}\text { Education in } \\
\text { agriculture }\end{array}$ & $12.55 \pm 2.79$ & $16.97 \pm 2.95$ & $13.33^{* *}$ & $12.54 \pm 2.68$ & $12.7 \pm 2.59$ & $0.52 \mathrm{NS}$ & $0.03 \mathrm{NS}$ & $13.32^{* * *}$ \\
\hline $\begin{array}{l}\text { Career } \\
\text { opportunities }\end{array}$ & $8.74 \pm 2.21$ & $17.09 \pm 2.90$ & $28.04 * *$ & $8.71 \pm 2.13$ & $8.88 \pm 2.12$ & $0.69 \mathrm{NS}$ & $0.11 \mathrm{NS}$ & $27.99 * *$ \\
\hline $\begin{array}{l}\text { General } \\
\text { attitudes toward } \\
\text { agriculture }\end{array}$ & $44.66 \pm 8.42$ & $60.63 \pm 9.03$ & $15.84^{* *}$ & $44.60 \pm 8.26$ & $45.05 \pm 8.07$ & $0.47 \mathrm{NS}$ & $0.06 \mathrm{NS}$ & $15.75^{* *}$ \\
\hline
\end{tabular}

Gr I - Experimental group Gr II - Control group

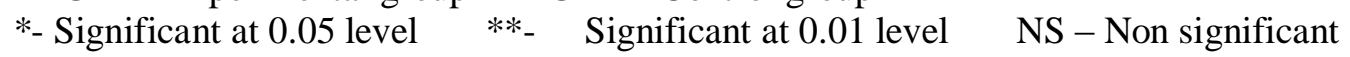




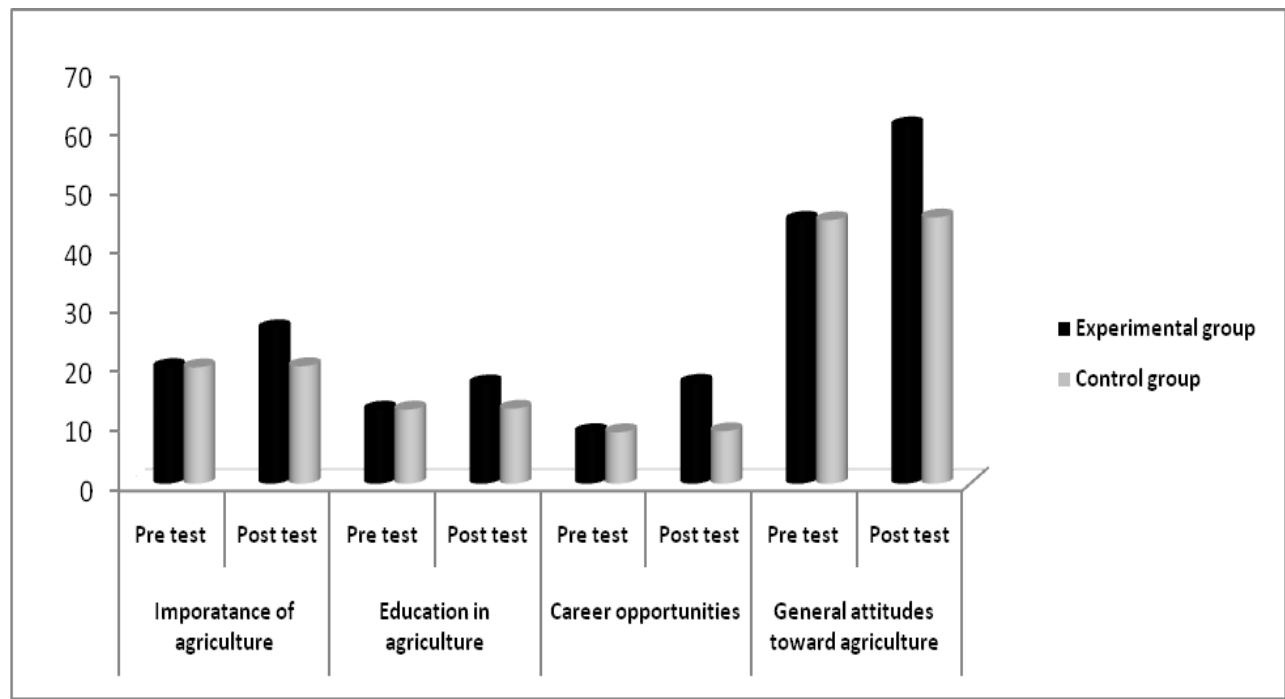

Fig 1 Comparision between mean scores of rural school students' awareness about agriculture in control and experimental groups

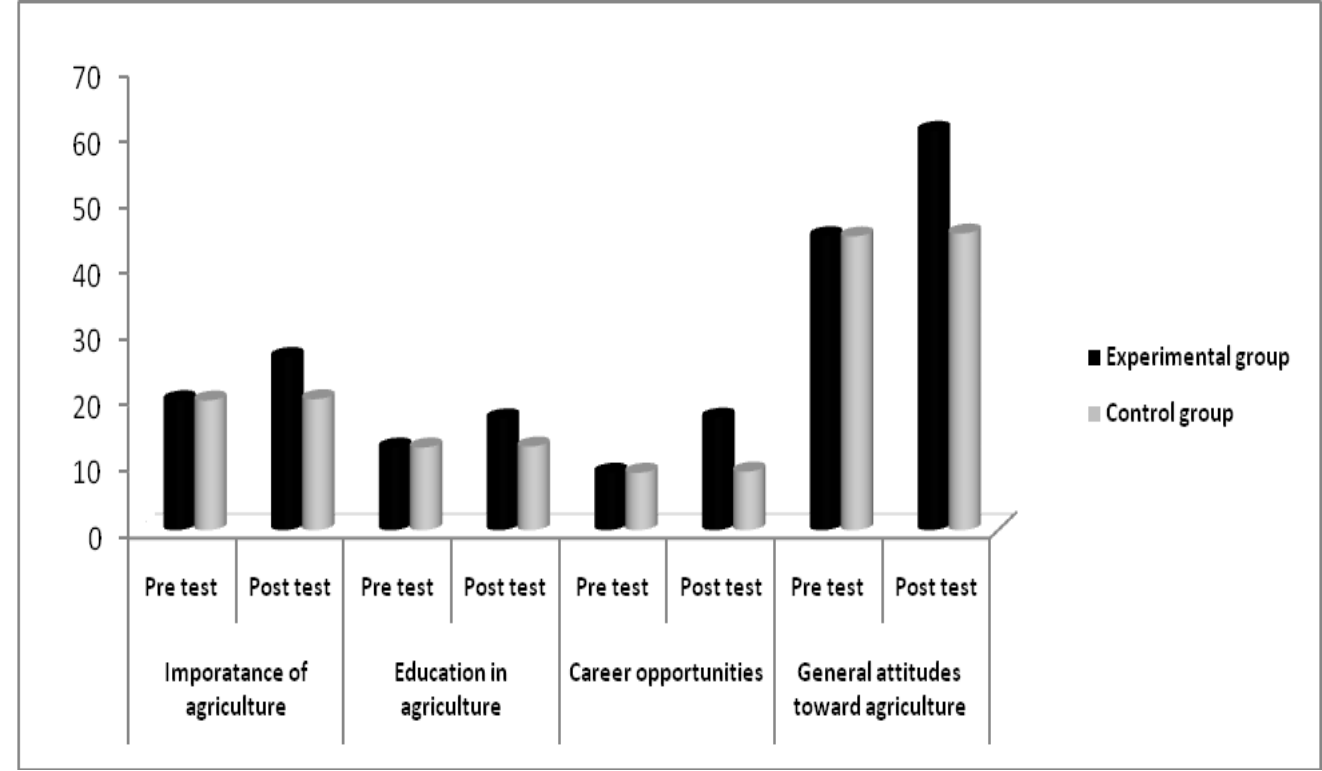

Fig 2 Comparision between mean scores of rural school students' attitudes toward agriculture in control and experimental groups 